\title{
Next Generation Photosensitive Dielectric Materials for Advanced Packaging Applications
}

\author{
Takeharu Motobe*, Masayuki Ohe, Noriyuki Yamazaki, and Tetsuya Enomoto \\ Technology Development Center, Hitachi Chemical DuPont MicroSystems, Ltd., \\ 4-13-1 Higashi-cho, Hitachi, Ibaraki 317-8555, Japan \\ *takeharu.motobe@hdms.co.jp
}

\begin{abstract}
Hitachi Chemical DuPont MicroSystems (HDMS) is a supplier of photosensitive negative-tone polyimides (PI) and positive-tone poly(benzoxazole)s (PBO) for use as protection layers in semiconductor ICs or as dielectrics for re-distribution layers in Fan-in or Fan-out wafer level packages. These materials offer an easy manufacturing process as well as ensuring high reliability in semiconductor packages. Recently, design rules and structures for next generation packages are advancing in order to achieve higher end multi-functionality. In accordance with this trend, next generation PIs and PBOs need to be developed to address new challenges that include lithographic properties, in-process compatibility and end-use properties and, in this paper, the latest material sets developed by HDMS will be introduced for advanced packaging applications. The $1^{\text {st }}$ material set is a low stress photosensitive PI designed especially as a protection layer in advanced process node semiconductor ICs where warpage reduction and better protection capability for fragile low-k layers are needed. The $2^{\text {nd }}$ and $3^{\text {rd }}$ material sets are designed as low temperature curable photosensitive PI and PBO for use as dielectrics in Fan-out wafer level package to provide good applicability with future device designs as well as high package reliability by improving resolution, cured film properties, adhesion, insulation reliability, and others.
\end{abstract}

Keywords: Photosensitive PI and PBO, Low stress, High modulus, Low temperature curable, High resolution, Adhesion to $\mathrm{Cu}$, Insulation reliability

\section{Introduction}

Photosensitive polyimides (PI) and poly(benzoxazole)s (PBO) are widely used as protection layers for semiconductor IC chips and as dielectrics for re-distribution layers in wafer level packaging. For both material types, the manufacturing process is simplified as conventional photoresist processing is not needed for patterning and cured film properties such as elongation, heat resistance, chemical resistance, insulation property and adhesion etc. are so good that the reliability of the semiconductor package is ensured [1-7].

Recently, packaging technology has progressed towards higher performance and multifunctionality and which has resulted in requirements for photosensitive PIs and PBOs becoming more complex and sophisticated.

Regarding the application of protection layers for advanced process node semiconductor ICs, low residual stress and high modulus are required to enhance the protection of fragile low-k layers and to reduce wafer and IC chip warpage [8-10].

In the case of photosensitive dielectrics for fan-out wafer level packaging (FO-WLP), which is focused mainly on form factor and heterogeneous integration, low temperature curable materials below $200{ }^{\circ} \mathrm{C}$ are required to reduce warpage of the re-constituted wafer and minimize thermal damage on the embedded ICs [11-16]. In addition, higher resolution especially for via openings is also needed to meet future design rules for FO-WLP. Adhesion to $\mathrm{Cu}$ and insulation reliability are also important factors in ensuring advanced package reliability [17-19].

Based on these requirements for photosensitive dielectric materials, development programs are actively ongoing in HDMS and, in this paper, the current status of our latest photosensitive PIs and PBOs will be introduced. 


\section{Material sets}

Table 1 summarizes the HDMS material sets for advanced packaging applications and where PI 1 and PBO 1 are conventional materials typically cured at $300{ }^{\circ} \mathrm{C}$ or above.

Regarding new PI materials, PI 2 has been designed as the next version of PI 1 to address the need to enhance protection capability and reduce the stress in advanced process node semiconductor ICs while PI 3 is a new low temperature PI that can be cured at $200^{\circ} \mathrm{C}$ or below.

Regarding PBO materials, PBO 2 was the first material launched by HDMS that could be cured at $200{ }^{\circ} \mathrm{C}$. Further development has resulted in PBO 3 that has a wider cure temperature range and lithographic performance. Details of new materials are described in the following sections.

Table 1. HDMS photosensitive PI \& PBO sets.

\begin{tabular}{|c|c|c|c|}
\hline Material & Tone & Cure temp. & Feature \\
\hline PI 1 & negative & $\begin{array}{c}\text { High } \\
\left(350-400^{\circ} \mathrm{C}\right)\end{array}$ & Conventional \\
\hline PI 2 & Negative & $\begin{array}{c}\text { High } \\
\left(300-400{ }^{\circ} \mathrm{C}\right)\end{array}$ & $\begin{array}{c}\text { Low stress } \\
\text { High modulus }\end{array}$ \\
\hline PI 3 & Negative & $\begin{array}{c}\text { Low } \\
\left(175-250^{\circ} \mathrm{C}\right)\end{array}$ & Low temp. cure \\
\hline PBO 1 & Positive & $\begin{array}{c}\text { High } \\
\left(300-350^{\circ} \mathrm{C}\right)\end{array}$ & Conventional \\
\hline PBO 2 & Positive & $\begin{array}{c}\text { Low } \\
\left(200-250^{\circ} \mathrm{C}\right)\end{array}$ & Low temp.cure \\
\hline PBO 3 & Positive & $\begin{array}{c}\text { Low } \\
\left(175-250^{\circ} \mathrm{C}\right)\end{array}$ & $\begin{array}{l}\text { Low temp. cure } \\
\text { High resolution }\end{array}$ \\
\hline
\end{tabular}

\section{Low stress negative-tone PI}

Residual stress is closely related to coefficient of thermal expansion (CTE) and modulus of the PI as shown in the equation (1) [20]. However, as high modulus enhances protection of the device, it was decided to focus on lowering CTE to reduce stress.

$$
\sigma=\int \alpha(\mathrm{T}) \mathrm{E}(\mathrm{T}) \mathrm{dT}
$$

$\sigma:$ Residual stress

$\alpha:$ CTE difference between PI and substrate

$\mathrm{E}$ : Modulus of PI

\subsection{Cured film properties}

To lower the CTE of the PI, a rigid moiety was incorporated into the PI 2 polymer backbone. As shown in Table 2, this has the effect, in addition to increasing the modulus, of decreasing the CTE and the residual stress to below $20 \mathrm{MPa}$ (almost half that of PI 1) and which significantly reduces the warpage of the IC as compared to PI 1 (Fig. 1).
Table 2. Cured film properties of PI 1 and PI 2.

\begin{tabular}{|c|c|c|c|c|}
\hline Item & PI 1 & \multicolumn{3}{|c|}{ PI 2 } \\
\hline Cure temp. $\left({ }^{\circ} \mathrm{C}\right)$ & 375 & 320 & 350 & 380 \\
\hline Tensile strength $(\mathrm{MPa})$ & 200 & 202 & 182 & 196 \\
\hline Elongation $(\%)$ & 45 & 31 & 19 & 14 \\
\hline Modulus $(\mathrm{GPa})$ & 3.5 & 4.7 & 5.1 & 5.1 \\
\hline$T \mathrm{~g}\left({ }^{\circ} \mathrm{C}\right)$ & 320 & 299 & 313 & 354 \\
\hline $\mathrm{CTE}\left(\times 10^{-6} /{ }^{\circ} \mathrm{C}\right)$ & 35 & 31 & 18 & 10 \\
\hline$T \mathrm{~d}_{5}\left({ }^{\circ} \mathrm{C}\right)$ & 480 & 363 & 436 & 509 \\
\hline Residual stress $(\mathrm{MPa})$ & 34 & 19 & 18 & 17 \\
\hline
\end{tabular}

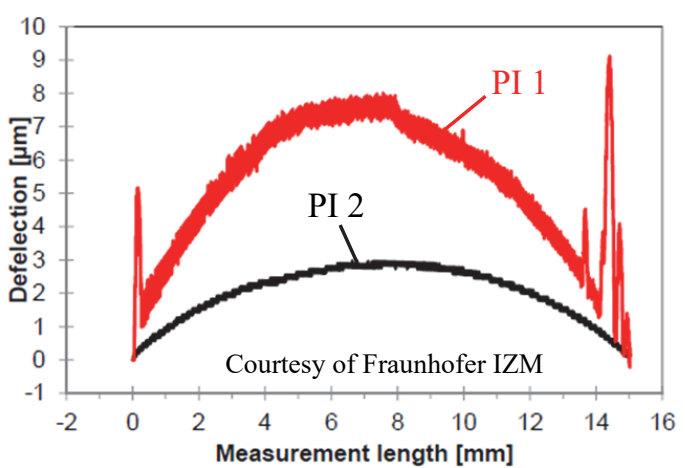

Fig. 1. Warpage measurement results of PI 1 and PI 2 (Chip size : $15 \mathrm{~mm} \times 15 \mathrm{~mm}$, Chip thickness : $300 \mu \mathrm{m}$ ).

\subsection{Adhesion performance}

While rigid PIs generally require a primer treatment to ensure good adhesion, PI 2 has been designed as a self-priming material. As shown in Fig. 2, the adhesion performance of PI 2 passes the stud pull test to Si after $300 \mathrm{~h}$ highly accelerated storage test (HAST, $130{ }^{\circ} \mathrm{C} / 85 \% \mathrm{RH}$ ).

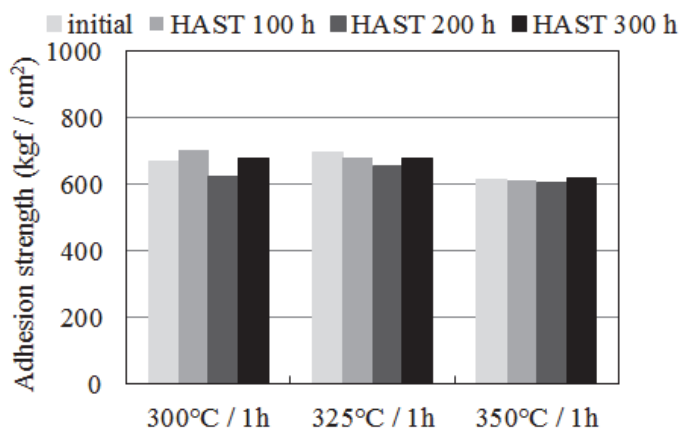

Fig. 2. Stud pull test results to Si of PI 2.

\section{Low temperature curable negative-tone PI}

When cured at low temperatures, the cured film properties and adhesion to $\mathrm{Cu}$ of PI 1 are drastically degraded. In addition, it is not possible for PI 1 to process $5 \mu \mathrm{m}$ via openings. To improve these features, a new cross-linker and adhesion promoter were introduced and the photo-package was changed resulting in a new low temperature curable negative-tone PI (PI 3). 


\subsection{Lithographic performance}

Figure 3 shows the via cross-sections of PI 3 where a smooth side wall profile $\left(70-80^{\circ}\right.$ angle to the substrate surface) with no crowning at the top edge of the opening was successfully obtained with a $5 \mu \mathrm{m}$ via opening.

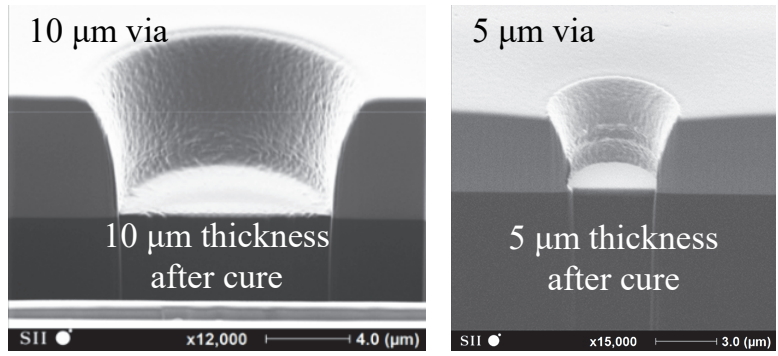

Fig. 3. Via cross-section of PI 3.

\subsection{Cured film properties}

As summarized in Table 3, PI 3 has acceptable cured film properties over a cure temperature range of $175-250^{\circ} \mathrm{C}$.

Table 3. Cured film properties of PI 3.

\begin{tabular}{|c|c|c|c|c|}
\hline Item & \multicolumn{5}{|c|}{ PI 3} \\
\hline Cure temp. $\left({ }^{\circ} \mathrm{C}\right)$ & 175 & 200 & 225 & 250 \\
\hline Tensile strength $(\mathrm{MPa})$ & 202 & 197 & 207 & 188 \\
\hline Elongation $(\%)$ & 52 & 55 & 58 & 48 \\
\hline Modulus $(\mathrm{GPa})$ & 3.0 & 2.9 & 2.8 & 2.9 \\
\hline $\mathrm{Tg}\left({ }^{\circ} \mathrm{C}\right)$ & 211 & 217 & 234 & 253 \\
\hline $\mathrm{CTE}\left(\times 10^{-6} /{ }^{\circ} \mathrm{C}\right)$ & 68 & 68 & 58 & 57 \\
\hline $\mathrm{Td}_{5}\left({ }^{\circ} \mathrm{C}\right)$ & 314 & 320 & 336 & 342 \\
\hline Residual stress $(\mathrm{MPa})$ & \multicolumn{5}{|c|}{25} \\
\hline
\end{tabular}

In addition, the overall $\%$ film retention from coating to final cure with PI 3 is $75-80 \%$. As compared to $45-50 \%$ with PI 1 , this is higher due to its lower cure shrinkage. This feature also can improve surface planarity in multi-layer coating where, as indicated in Fig.4, PI 3 shows higher planarity after double coating as compared to PI 1.
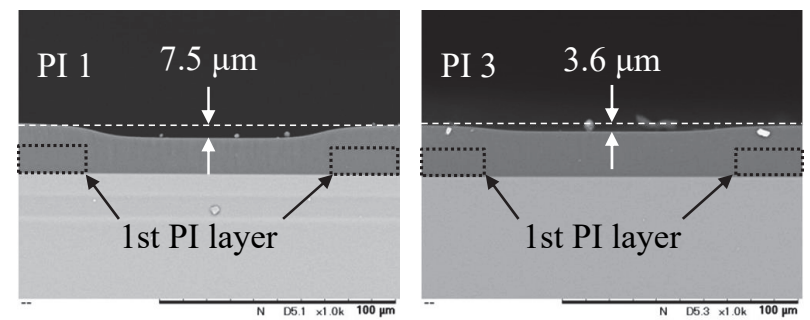

Fig. 4. Surface planarity at double coating (1st PI layer : $10 \mu \mathrm{m}$ thickness).

\subsection{Adhesion to $\mathrm{Cu}$}

As shown in Fig. 5, PI 3 passes the stud pull test to $\mathrm{Cu}$ after $300 \mathrm{~h}$ pressure cooker test (PCT, 121 ${ }^{\circ} \mathrm{C} / 100 \% \mathrm{RH}$ ) even when cured at $175^{\circ} \mathrm{C}$.

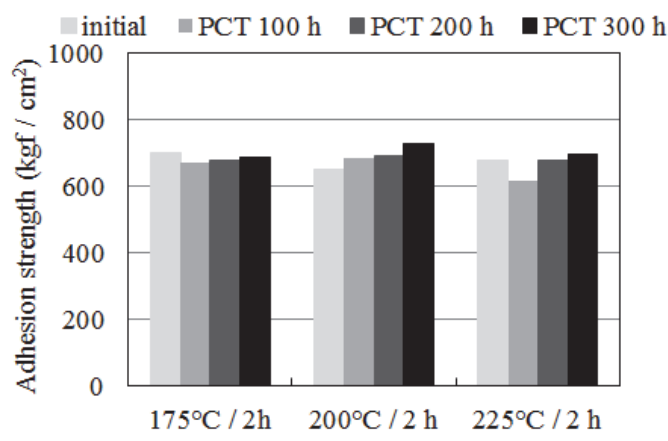

Fig. 5. Stud pull test results to $\mathrm{Cu}$ of PI 3 .

\subsection{Insulation reliability}

In cooperation with Hitachi Chemical Packaging Solution Center, a $2 \mu \mathrm{m} \mathrm{L} / \mathrm{S}$ pattern as shown in Fig. 6 was assembled using PI 3 and subjected to Bias-HAST $\left(130{ }^{\circ} \mathrm{C} / 85 \% \mathrm{RH}, \mathrm{DC} 3.3 \mathrm{~V}\right)$. The test result is shown in Fig. 7 and where no short circuiting, dendrite formation, or delamination was observed indicating that PI 3 can be used for future finer $\mathrm{L} / \mathrm{S}$ designs.

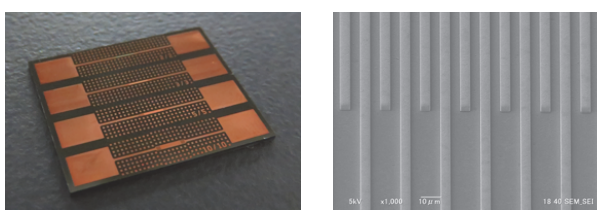

Fig. $6.2 \mu \mathrm{m} \mathrm{L/S} \mathrm{pattern} \mathrm{for} \mathrm{Bias-HAST.}$

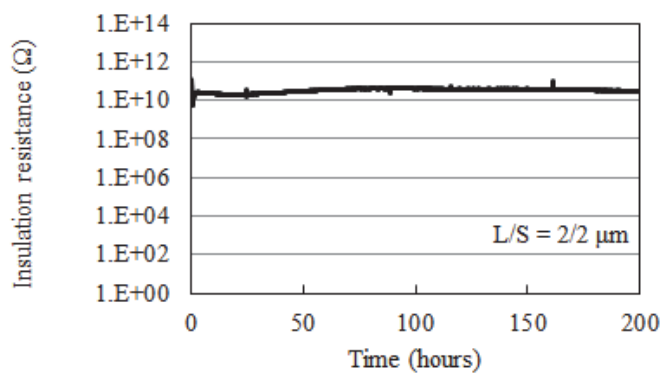

Fig. 7. Bias-HAST result of PI 3.

\section{Low temperature curable positive-tone PBO}

While PBO 2 was the first low temperature curable positive-tone PBO launched by HDMS [21] that could be cured at $200{ }^{\circ} \mathrm{C}$, improvements in lithographic performance, adhesion to $\mathrm{Cu}$ and insulation reliability are needed to meet current FOWLP requirements. To address these needs, the photo-package was changed and a new cross-linker and adhesion promoter were introduced resulting in a new low temperature curable PBO (PBO 3). 
5.1. Lithographic performance

A comparison of the lithographic performance between PBO 2 and PBO 3 is listed in Table 4 and where no significant differences in lithographic performance are observed with a $7 \mu \mathrm{m}$ cure film thickness. However, due to the higher dissolution contrast obtained with PBO 3 from the change in photo-package, a higher resolution can be achieved with thick films greater than $15 \mu \mathrm{m}$ thickness after cure. Cross-sections of PBO 3 lithographic patterns are shown in Fig. 8 and where a smooth side wall profile ( $70-80^{\circ}$ angle to substrate surface) with no crowning at the top edge was obtained.

Table 4. Lithographic performance of PBO 2 and $\mathrm{PBO}$ 3.

\begin{tabular}{|c|c|c|c|c|}
\hline Material & $\begin{array}{c}\text { Thickness } \\
\text { after } \\
\text { soft-bake } \\
(\mu \mathrm{m})\end{array}$ & $\begin{array}{c}\text { Exposure } \\
\text { energy } \\
\left(\mathrm{mJ} / \mathrm{cm}^{2}\right)\end{array}$ & $\begin{array}{c}\text { Thickness } \\
\text { after cure } \\
(\mu \mathrm{m})\end{array}$ & $\begin{array}{c}\text { Resolution } \\
(\mathrm{L} / \mathrm{S}, \mu \mathrm{m})\end{array}$ \\
\hline \multirow{2}{*}{ PBO 2 } & 11.2 & 230 & 7.3 & 2 \\
\cline { 2 - 5 } & 19.8 & $>1000$ & 12.2 & $10-15$ \\
\hline \multirow{3}{*}{ PBO 3 } & 11.4 & 180 & 7.2 & 2 \\
\cline { 2 - 5 } & 20.3 & 500 & 13.1 & 3 \\
\cline { 2 - 5 } & 27.4 & 640 & 15.6 & 3 \\
\hline
\end{tabular}

Soft bake: $110{ }^{\circ} \mathrm{C} / 180 \mathrm{~s}$, Cure: $200{ }^{\circ} \mathrm{C} / 2 \mathrm{~h}$.
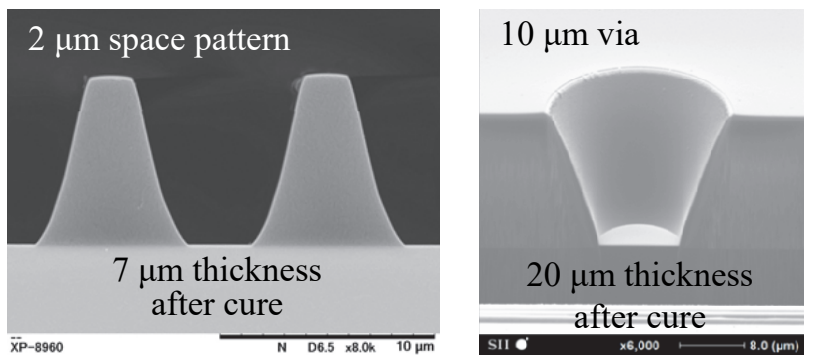

Fig. 8. Cross-sections of lithographic pattern of PBO 3.

\subsection{Cured film properties}

PBO 3 cured film properties, as summarized in Table 5, are acceptable even when cured at $175^{\circ} \mathrm{C}$. PBO 3 also has a wide cure temperature margin over the cure temperature range of $175-250{ }^{\circ} \mathrm{C}$.

Table 5. Cured film properties of PBO 3.

\begin{tabular}{|c|c|c|c|c|}
\hline Item & \multicolumn{4}{|c|}{ PBO 3 } \\
\hline Cure temp. $\left({ }^{\circ} \mathrm{C}\right)$ & 175 & 200 & 225 & 250 \\
\hline Tensile strength $(\mathrm{MPa})$ & 160 & 150 & 120 & 120 \\
\hline Elongation $(\%)$ & 65 & 70 & 70 & 55 \\
\hline Modulus $(\mathrm{GPa})$ & 2.1 & 2.0 & 1.8 & 1.7 \\
\hline $\mathrm{Tg}\left({ }^{\circ} \mathrm{C}\right)$ & 240 & 245 & 255 & 270 \\
\hline $\mathrm{CTE}\left(\times 10^{-6} /{ }^{\circ} \mathrm{C}\right)$ & 75 & 75 & 80 & 84 \\
\hline $\mathrm{Td} 5\left({ }^{\circ} \mathrm{C}\right)$ & 300 & 320 & 340 & 365 \\
\hline Residual stress $(\mathrm{MPa})$ & \multicolumn{5}{|c}{27} \\
\hline
\end{tabular}

\subsection{Adhesion to $\mathrm{Cu}$}

As clearly indicated in Fig. 9, no delamination between PBO 3 and $\mathrm{Cu}$ surface was observed and PBO 3 when cured at $175{ }^{\circ} \mathrm{C}$ passes the stud pull test after $300 \mathrm{~h}$ PCT.

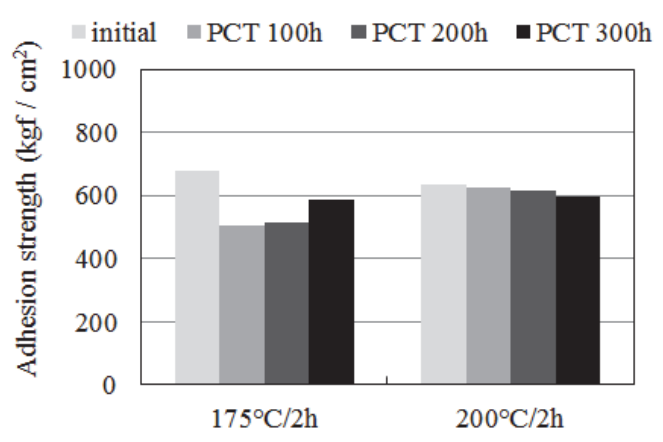

Fig. 9. Stud pull test results to $\mathrm{Cu}$ of $\mathrm{PBO} 3$.

\subsection{Insulation reliability}

As shown in Fig. 10, PBO 3 shows no short circuiting, dendrite formation or delamination during Bias-HAST with a $2 \mu \mathrm{m} \mathrm{L} / \mathrm{S}$ pattern $(130$ ${ }^{\circ} \mathrm{C} / 85 \% \mathrm{RH}$, DC $3.3 \mathrm{~V}$ ).

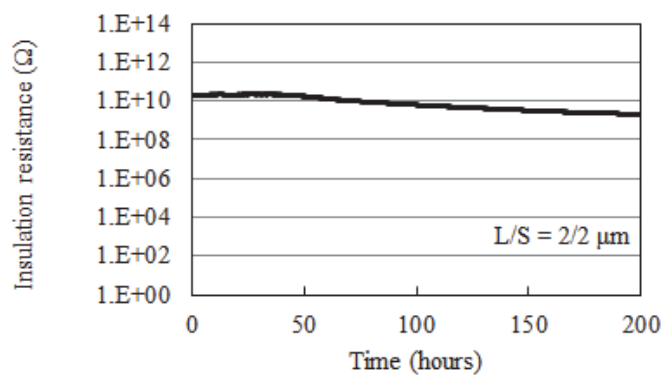

Fig. 10. Bias-HAST result of PBO 3.

\section{Package reliability}

In cooperation with Hitachi Chemical Packaging Solution Center, a FO-WLP test vehicle was assembled with both PI 3 and PBO 3 to evaluate in-process compatibility as well as package reliability at the component and board level. A cross-section of the test vehicle with some specifications is shown in Fig. 11.

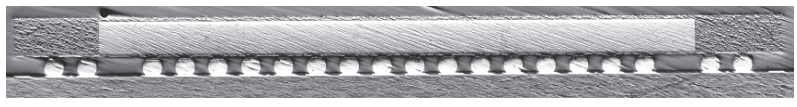

Package: size $9.8 \mathrm{~mm}$ x $9.8 \mathrm{~mm}$, thickness $450 \mu \mathrm{m}$ Chip: size $7.3 \mathrm{~mm}$ x $7.3 \mathrm{~mm}$, thickness $400 \mu \mathrm{m}$ Dielectric: 2 layers ( $7 \mu \mathrm{m}$ thickness each) Bumps: number 336, pitch $300 \mu \mathrm{m}$

Fig. 11. Cross-section of FO-WLP test vehicle. 
Regarding the in-process compatibility of PI 3 and PBO 3, no defects were observed with any of the processing steps that included coating, patterning, $\mathrm{Cu}$ line formation (seed sputter, resist formation, plating, resist stripping, and seed etching ) and bumping.

Table 6 summarizes the reliability test results at component and board level for PI 3 and PBO 3 during thermal cycle testing (TCT).

For the component level evaluation, no defects in appearance such as crack and delaminationwere observed after multi-reflow treatment (85 ${ }^{\circ} \mathrm{C} / 85 \% \mathrm{RH} / 168 \mathrm{~h}+10$ times reflow $\left.\left(\max 260^{\circ} \mathrm{C}\right)\right)$ followed by up to 1000 cycles TCT $\left(-65{ }^{\circ} \mathrm{C} / 15\right.$ $\left.\min \leftrightarrow 150^{\circ} \mathrm{C} / 15 \mathrm{~min}\right)$.

For the board level evaluation, the FO-WLP test vehicle was mounted onto an organic substrate through reflow treatment so that the electrical resistance through $\mathrm{Cu}$ lines in the dielectric layer and on the substrate can be measured across a daisy chain pattern. From the test results, no electrical failure was observed up to 1000 cycles TCT indicating that both PI 3 and PBO 3 have good package reliability performance.

Table 6. Package reliability of PI 3 and PBO 3.

\begin{tabular}{|c|c|c|c|c|}
\hline TCT & \multicolumn{2}{|c|}{ PI 3} & \multicolumn{2}{c|}{ PBO 3 } \\
\cline { 2 - 5 } cycles & Component & Board & Component & Board \\
\hline initial & no defect & no failure & no defect & no failure \\
\hline 200 & no defect & no failure & no defect & no failure \\
\hline 400 & no defect & no failure & no defect & no failure \\
\hline 600 & no defect & no failure & no defect & no failure \\
\hline 800 & no defect & no failure & no defect & no failure \\
\hline 1000 & no defect & no failure & no defect & no failure \\
\hline
\end{tabular}

\section{Conclusion}

To meet the requirements on next generation photosensitive dielectric materials for advanced packaging applications, three promising candidate materials have been developed.

PI 2 is a low stress negative-tone PI suitable for protection layer application where a rigid moiety was introduced into the polymer backbone to lower of the CTE and reduce residual stress. In addition, the higher modulus of PI 2 as compared to the conventional PI 1 enhances protection capability

PI 3 and PBO 3 are two low temperature curable materials suitable for use as dielectrics in FO-WLP applications. By changing the photo-package as well as adopting a new cross-linker and adhesion promoter with both material sets, lithographic performance, cured film properties and adhesion to
$\mathrm{Cu}$ are noticeably improved at a low temperature cure around $200^{\circ} \mathrm{C}$. Both materials also show good insulation reliability at $2 \mu \mathrm{m} \mathrm{L} / \mathrm{S}$ pattern and good package reliability at component and board level.

While the three material sets introduced in this paper meet current performance requirements, further development programs in HDMS on photosensitive dielectric materials are on-going to address future technology needs.

\section{References}

1. H. Makabe, T. Banba, and T. Hirano, J. Photopolym. Sci. Technol., 10 (1997) 307.

2. M. Tomikawa, M. Suwa, S. Yoshida, Y. Fujita, R. Okuda, and G. Ohbayashi, J. Photopolym. Sci. Technol., 13 (2000) 357.

3. K. Yamamoto and T. Hirano, J. Photopolym. Sci. Technol., 15 (2002) 173.

4. R. Rubner, J. Photopolym. Sci. Technol., 17 (2004) 685

5. N. Anzai, M. Fujita, and A. Fujii, Proc. 64th ECTC, (2014) 829.

6. M. Fujita, A. Fujii, S. Shimoda, and Y. Kariya, Proc. IMAPS 2015, 505.

7. Y. C. Chen, K. Wan, C.A. Chang, and R. Lee, Proc. 67th ECTC, (2017) 2040.

8. M. Yoshida, T. Hirata, M. Fujita, N. Anzai, and N. Tamura, J. Photopolym. Sci. Technol., 27 (2014) 357.

9. K. Sakamaki, Y. Kariya, and M. Niwa, Proc. Mate 2012, 449.

10. M. Niwa, K. Sakamaki, and Y. Kariya, Proc. ICEP 2012, 15.

11. M. Töpper, T. Fischer, V. Bader, K. D. Lang, N. Matsuie, T. Motobe, T. Minegishi, and M. Knaus, Proc. ICEP 2011, 452.

12. Y. Shoji, Y. Masuda, K. Hashimoto, K. Isobe, Y. Koyama, and R. Okuda, Proc. 66th ECTC, (2016) 1707.

13. Y. Shoji, Y. Koyama, Y. Masuda, K. Hashimoto, K. Isobe, and R. Okuda, J. Photopolym. Sci. Technol., 29 (2016) 277.

14. T. Sasaki, J. Photopolym. Sci. Technol., 29 (2016) 379.

15. F. Windrich, E. J. Kappert, M. Malanin, K. J. Eichhorn, L. Häußler, N. E. Benes, and B. Voit, Eur. Polym. J., 84 (2016) 279.

16. T. Enomoto, S. Abe, D, Matsukawa, T. Nakamura, N. Yamazaki, N. Saito, M. Ohe, and T. Motobe, Proc. ICEP 2017, 498.

17. M. Tomikawa, K. Matsumura, Y. Shoji, Y. Tatsuta, and R. Okuda, J. Photopolym. Sci. Technol., 30 (2017) 181. 
18. K. Mitsukura, S. Abe, M. Toba, T. Minegishi, and K. Kurafuchi, Proc. IMAPS 2016, 165.

19. H. Kudo, R. Kasai, J. Suyama, M. Takeda, Y. Okazaki, H. Iida, D. Kitayama, T. Sasao, K. Sakamoto, H. Sato, S. Yamada, and S. Kuramochi, Proc. 67th ECTC, (2017) 1849.
20. J. H. Lim, M. H. Han, J. Y. Lee, Y. Y. Earmme, S. B. Lee, and S. Im, J. Mechanic. Sci. Technol., 22 (2008) 1483.

21. T. Minegishi, R. Nogita, K. Iwashita, T. Kawamura, M. Ohe, and N. Matsuie, Hitachi Chemical Technical Report, 52 (2009) 13. 